\title{
AÇÕES PEDAGÓGICAS DO JARDIM ZOOLÓGICO DE SALVADOR E SUAS RELAÇÕES COM AS ESCOLAS
}

\author{
Nayane Regina Gomes Santos ${ }^{1}$ e Marco Antônio Leandro Barzano ${ }^{2}$ \\ 1. Bolsista PIBIC/CNPq, Graduando em Ciências Biológicas, Universidade Estadual de Feira de Santana, e-mail: \\ nayane.bioogia@gmail.com \\ 2. Orientador, Departamento de Educação, Universidade Estadual de Feira de Santana, e-mail: \\ marco.barzano@gmail.com
}

PALAVRAS-CHAVE: Ações Pedagógicas; Escola; Jardim Zoológico.

\section{INTRODUÇÃO}

O Museu, de acordo com Almeida (1997) é uma instituição permanente, sem fins lucrativos, que adquire, preserva, documenta, pesquisa e comunica para a educação e lazer. Diante disto, se acentua a necessidade do desenvolvimento de pesquisas com o intuito de desvelar suas interferências e potencialidades educativas por ser um instrumento que produz e atua na formação da cultura da sociedade.

Tendo em vista que, assim como relata Garcia (2006), "as instituições zoológicas, consideradas museus de educação não formal, são um dos lugares mais visitados no mundo todo, apresentando um grande potencial para prática educativa a partir dos elementos presentes em sua exibição e das diferentes atividades oferecidas pelos programas educacionais."

O presente trabalho procurou compreender e analisar as ações educativas no Jardim Zoológico de Salvador construído no século XIX, e sua relação com as escolas que visitam este museu, o público visitante compreendo a divulgação da ciência que este ambiente possibilita realizar.

Com a execução deste trabalho, pretendeu-se também: avaliar a percepção pública escolar junto às exposições do Jardim Zoológico; verificar e analisar os objetos zoológicos que compõem as exposições do Jardim Zoológico; analisar os materiais educativos do Jardim Zoológico; analisar ações que se estabelecem na relação museuescola. Com o intuito de destacar, com a realização desta pesquisa, novas informações que permeiam as ações pedagógicas desenvolvidas em Jardins zoológicos.

\section{METODOLOGIA}

O presente estudo foi realizado pelo período compreendido de um ano (Agosto de 2015 a Agosto de 2016) no Jardim Zoológico de Salvador, localizado na Tv. Alto de Ondina, s/n- Ondina, Salvador-ba, 400170-110. Durante o período analisado, foram realizadas entrevistas semiestruturadas composta por perguntas que tem como intuito a identificação dos participantes como os dados sobre o cargo que ocupa no museu; quanto tempo trabalha no Jardim Zoológico; bem como por questões norteadoras sobre como os mesmos entendem as ações pedagógicas desenvolvidas neste museu; como ocorre a relação do público visitante com os elementos expostos dentre outras.

Durante a realização das entrevistas foi informado aos entrevistados que as entrevistas seriam gravadas e que os mesmos teriam acesso ao material sempre que desejassem tanto as gravações quanto as transcrições. Para a realização da entrevista utilizei os roteiros de perguntas semiestruturadas. A escolha por esta metodologia baseia-se na concepção apresentada por Triviños (1987), quando o autor explica que a entrevista semiestruturada "[...] ao mesmo tempo em que valoriza a presença do 
investigador, oferece todas as perspectivas possíveis para que o informante alcance a liberdade e a espontaneidade necessárias, enriquecendo a investigação".

Os sujeitos de estudo deste trabalho foram os monitores, técnicas e o coordenador do Jardim Zoológico de Salvador, indivíduos estes que possuem conhecimentos relativos ao histórico deste Museu, a dinâmica do dia a dia, informações sobre as espécies ali encontradas, bem como propõem e fazem acontecer às atuais ações pedagógicas neste museu.

\section{RESULTADOS E/OU DISCUSSÃO}

A partir de entrevistas semiestruturadas, para a obtenção de dados, realizei visitas a algumas instituições museais situadas em Feira de Santana com a finalidade de levantar informações importantes as quais permitiram compreender os aspectos relacionados à fundação e Histórico dos Museus; quais os objetivos que norteiam a iniciativa para a montagem das exposições; para qual público determinada exposição é direcionada; como ocorrem as visitas e quais os suportes oferecidos ao público no momento das visitações; se este museu realiza exposições de caráter itinerante; como ocorre a troca das exposições temporárias e permanentes, bem como, a sua durabilidade destas e se esse acervo dos museus permitem que haja uma interação dos visitantes com os objetos expostos.

Através desse primeiro contato com a realidade da atmosfera que circunda os museus tornou-se claro que apesar do histórico, dos enfoques e temáticas que cada um dos museus desenvolve e trabalham sejam diferentes, todos compartilham o cuidado com a mediação das informações que se deseja partilhar com a montagem de determinada exposição ressaltando assim a importância e o entendimento do museu como um dos diversos meios de se propagar conhecimentos científicos para a população.

Foi por meio de entrevistas que nos foram concedidas pelas Técnicas da Área de Gestão Ambiental do Jardim Zoobôtanico de Salvador as quais concordaram em participar voluntariamente deste trabalho que se deu o início a pesquisa com o nosso objeto de estudo, o Jardim Zoológico de Salvador. Desta forma tomamos conhecimento acerca do histórico desde a fundação deste museu, no século XIX e a sua inauguração em 1958 através do Decreto Estadual nº 17.481, à construção deste zoológico que se estabeleceu com a finalidade cultural e o intuito de promover atividades preservacionistas e educacionais com foco especial às espécies ameaçadas de extinção e pertencentes à fauna brasileira construindo ambientação de recintos, como relata a técnica da gestão ambiental: “O principal foco da manutenção do museu é a conservação dos animais silvestres $e$ o bem-estar do animal, buscando medidas para minimizar as condições estressantes em que os animais se encontram durante as exposições, traçando medidas técnicas que torne o museu o mais similar possível das condições do seu habitat natural” ( $L$ e L $)$.

Foi por meio das entrevistas e visitação ao espaço museal que conhecemos os elementos de exposição que compõem o acervo do Jardim Zoobotânico de Salvador o qual, de acordo com as nossas entrevistadas, possui entre as suas principais atrações cerca de 1.756 animais, distribuídos em 86 espécies de aves, 38 espécies de mamíferos e 28 espécies de répteis.

De acordo com Souza e Marandino (2012) os jardins, sejam estes zoológicos ou botânicos, acumulam diversas funções tais como: científica, educacional, social, estética, histórica e ecológica. Nesse sentido torna-se evidente que esses museus são também responsáveis pela produção e divulgação de saberes. Objetivando-se compreender e analisar as ações educativas no Jardim Zoológico de Salvador e sua 
relação com as escolas foi questionado às técnicas da área ambiental, quais as ações pedagógicas são realizadas neste museu, e diante do relato das entrevistadas percebemos que este museu realiza iniciativas com caráter itinerante como um recurso educativo de maneira a viabilizar a veiculação dos saberes produzidos neste museu. As atividades realizadas listadas foram: Aprendendo no zôo; zôo especial; zôo em família; Cine zôo; Descobrindo o mundo e o Trilha na mata do zôo, além da presença de placas informativas por todo o zoológico bem como alguns Dioramas.

Assim como está corroborado no trabalho de Xavier (2013) quando se afirma que a itinerância é um recurso educativo utilizada em diversos projetos bem como em museus, e essa iniciativa facilita o acesso às produções educativas e culturais funcionando como um dispositivo difusor de informação, conhecimento, e propulsor da inclusão social.

As medidas educativas ofertadas pelos museus de ciências, dentre eles os Jardins Zoológicos, com relação aos espaços escolares, perpassam por uma tênue fronteira para que a mediação entre o ensino-aprendizagem não seja compreendida como um procedimento de escolarização do museu como discute Lopes (1991).

Através da realização de entrevistas, no que se refere à relação estabelecida entre o museu e as escolas, levantamos a informação de que as escolas que visitam o Jardim Zoobotânico buscam este museu com percepções diferentes. Algumas vezes a ida ao Jardim Zoológico de Salvador tem sido considerando por algumas escolas visitantes, apenas como um museu de lazer enquanto outras escolas têm um posicionamento diferente das anteriores reconhecendo os museus como um espaço não formal de educação que pode ser uma extensão para o aprendizado acerca dos conteúdos vistos em sala de aula.

Percebemos também que Jardim tem um grande percentual de visitação, mas, no entanto a maioria deste público é o escolar da rede privada é muito mais frequente que a pública já que esta não dispõe, muitas vezes, de recursos necessários para a chegada ao zoológico a visitação eles apresentam conhecimentos prévios, em relação ao que será visto durante a ronda e é possível neste momento perceber uma interação dos alunos com os monitores enriquecendo assim a atividade. Essa interação com o público visitante não ocorre apenas nas visitas guiadas.

Outra preocupação do museu está relacionada ao cuidado com relação à fala adequada a cada um destes visitantes, demonstrando assim que esta instituição está sempre preocupada com seu o papel de difusor de conhecimento e estabelece metodologias, ações para que esta função ocorra de modo satisfatório. È nítido que grande parte do intercâmbio do saber está atribuída aos monitores ou mediadores, no entanto a compreensão dos objetivos propostos na exposição não pode depender da exclusivamente da presença dos mesmos assim como Marandino (2003) relata os monitores não são imprescindíveis e as exposições não podem depender deles para serem compreendidas. Por outro lado, talvez seja através da mediação humana a melhor forma de obter um aprendizado correto dos conceitos abordados nas exposições

Logo após as entrevistas desenvolvemos outra etapa da pesquisa: fizemos nossa própria visita ao museu objetivando verificar e analisar os objetos zoológicos que compõem as exposições do Jardim Zoológico e obter nossas impressões sobre a nossa visita ao museu.

O início do roteiro começa pela sala de educação ambiental onde são passadas as orientações aos visitantes sobre o cuidado de não alimentar os animais, de não estressálos, de caminhar sempre junto um do outro para que ninguém se perca, sobre a necessidade de prestar atenção a fala dos monitores. Fomos conduzidos pelos monitores, aos recintos dos animais e em cada um desses locais são apresentadas as características hábitos de vida dos animas observados. É neste momento que há bastante 
troca de saberes entre o público visitante e os mediadores e se estabelece a adequação da fala e intermediação das informações ao grupo que está sendo guiado.

Ao término do roteiro tornou-se nítido que o conhecimento promovido por Museus ainda são consultados e reconhecidos e estes museus continuam desenvolvendo um importante papel de estabelecer a troca de conhecimento às gerações, de modo a manter este conhecimento vivo.

\section{CONSIDERAÇÕES FINAIS}

Com base nas análises e discussões desenvolvidas, durante o período de um ano, por meio das entrevistas, pode-se afirmar que a relação museu-escola se estabelece entre o Jardim Zoológico de Salvador e as escolas que o visitam, por meio das interações colaborativas entre os objetos expostos; o público visitante e os mediadores deste espaço buscando, por meio deste contato, promover uma construção significativa do ensino aprendizagem de forma bastante eficiente.

\section{REFERÊNCIAS}

ALMEIDA, A.M. Desafios da relação museu escola. São Paulo 1997.

GARCIA, V. A. R. O processo de aprendizagem no Zoológico de Sorocaba: análise da atividade educativa visita orientada a partir dos objetos biológicos. Dissertação (Mestrado em Educação). Faculdade de Educação da Universidade de São Paulo, 2006. LOPES, M. M. A favor da desescolarização dos Museus. Educação e Sociedade, v. s/n, n. 40, p. 443-455, 1991.

MARANDINO, Martha. Enfoque de educação e comunicação nas bioexposições de museus de ciências. São Paulo, 2003.

SOUZA, M.P.C; MARANDINO, M. jardim botânico e público: trajetórias educacionais. In: SELLES , S.E; CASSAB, M. currículo docência e cultura. Niterói: Eduff, 2012

TRIVIÑOS, Augusto. Introdução a pesquisa em ciências sociais: a pesquisa qualitativa em educação: o positivismo, a fenomenologia, o marxismo. São Paulo, SP: Atlas, 2008. $175 \mathrm{p}$.

XAVIER, D.W. Museus em movimento: uma analise sobre experiências museológicas itinerantes. Universidade Lusófona de Humanidades e Tecnologias. In: cadernos de sociomuseologia-2-2013(vol.46). 